\section{Estudo \\ CoDebate}

em Testão

Plamejamento
Revista Estudo \& Debate, Lajeado, v. 26, n. 4, 2019. ISSN 1983-036X DOI: http://dx.doi.org/10.22410/issn.1983-036X.v26i4a2019.2194

\title{
QUALIDADE DE VIDA EM PROPRIEDADES PRODUTORAS DE LEITE DE IMIGRANTE/RS
}

\author{
Djéssica Elis Kroth ${ }^{1}$, Claudete Rempel ${ }^{2}$, Mônica Jachetti Maciel ${ }^{3}$, Cinthia Goettens ${ }^{4}$, \\ Ana Paula de Borba Morás 5
}

\begin{abstract}
Resumo: Teve-se como objetivo deste estudo avaliar a percepção de Qualidade de Vida (QV) dos trabalhadores rurais nas propriedades leiteiras de Imigrante/RS. Para tanto, foi aplicado o questionário WHOQOL-bref e realizada entrevista semiestruturada a nove indivíduos, possibilitando verificar que a média de QV destes foi 82,2 (DP 7,1), classificando-a como boa. Contudo, analisando os escores dos questionários nos diferentes domínios analisados, percebe-se que destes o Social apresenta os melhores escores $(90,7$ DP 12,1) e que o Físico apresenta os piores (76,2 DP 12,8). A média do domínio Físico difere estatisticamente do Social, assim como o Social do Psicológico pelo teste de Tukey $\mathrm{p}<0,05$. Conclui-se que, prevalece a percepção positiva quanto a QV, embora que algumas percepçóes negativas tenham sido anotadas durante as entrevistas.
\end{abstract}

Palavras-chave: Bem-estar. Agricultores. Produção de leite. WHOQOL-bref

\section{QUALITY OF LIVING IN PROPERTIES WITH MILK PRODUCTION OF IMIGRANTE/RS}

\begin{abstract}
The objective of this study was evaluate the perception of QL of rural workers in the Imigrante/RS market. To that end, nine individuals were applied to the WHOQOL-bref questionnaire and a mean of QL was obtained, 82.2 (SD 7.1), which was classified as good. However, analyzing the scores of the questionnaires in the
\end{abstract}

1 Bióloga. Universidade do Vale do Taquari - Univates

2 Bióloga. Doutora em Ecologia. Docente do Centro de Ciências Médicas e dos Programas de Pós-Graduação em Ambiente e Desenvolvimento e em Sistemas Ambientais Sustentáveis da Universidade do Vale do Taquari - Univates

3 Bióloga. Doutora em Ciências Veterinárias. Docente do Centro de Ciências Biológicas e da Saúde e do Programa de Pós-Graduação em Sistemas Ambientais Sustentáveis da Universidade do Vale do Taquari Univates

4 Acadêmica de Enfermagem. Bolsista de Iniciação Científica PROBIC/FAPERGS da Universidade do Vale do Taquari - Univates

5 Acadêmica de Ciências Biológicas, Bacharelado. Bolsista de Iniciação Científica da Universidade do Vale do Taquari - Univates 
different domains analyzed, we can see that the Social presentations demonstrate the best scores (90.7 SD 12.1) and that the Physical presents the worst (76.2 SD 12.8). The mean of the Physical domain differs statistically from the Social, as does the Social from the Psychological by the Tukey test $\mathrm{p}<0.05$. It was conclude that the positive perception about QL prevails, despite some negative perceptions as noted during interviews.

Keywords: Well-being. Farmers. Milk production. WHOQOL-bref

\section{INTRODUÇÁO E REFERENCIAL TEÓRICO}

O agronegócio tem uma grande importância econômica e social no mercado brasileiro, pois está diretamente relacionado à geração de emprego nos municípios. A produçấo de leite virou uma atividade economicamente significativa para o país, praticada particularmente por pequenos produtores. Esta atividade favorável tem colaborado para o campo agropecuário, visto que ao estipular mais renda e empregos aos produtores, tem mais estabilidade no campo (FARIÑA et al., 2017).

Alguns fatores têm levado a necessidade do aumento da jornada de trabalho no campo e na diversificaçáo das atividades a serem desenvolvidas, pois há uma grande necessidade do aumento da produçáo de leite e ao mesmo tempo os produtos primários comercializados pelas propriedades são desvalorizados devido ao aumento de custo da produçáo (CAVALHEIRO et al., 2014).

A agricultura familiar brasileira distingue-se pelo senso agropecuário como uma estável atividade econômica, encarregada de fornecer uma variada produção de alimentos saudáveis, processados em pequenos campos, por pequenos agricultores familiares que são donos da própria terra (IBGE, 2006).

Os produtores leiteiros precisam desenvolver inúmeras funções diárias, como a alimentação e tratamento do gado; preparação do animal para a ordenha e o armazenamento do leite; limpeza do ambiente e do material utilizado entre outras (CAVALHEIRO et al., 2014).

Os produtores de leite possuem pouco tempo livre para se envolver em outras tarefas não sendo as profissionais. O serviço de ordenha é apenas um dos trabalhos desenvolvidos na agricultura, pois muitos agricultores buscam outras atividades, com o intuito de aumentar a renda familiar e aproveitar os espaços existentes na propriedade (CAVALHEIRO et al., 2014).

O conceito de qualidade de vida manifestou-se devido ao interesse de cientistas onde ocorreu um movimento dentro das ciências humanas e biológicas com a finalidade de valorizar as questóes mais amplas que o controle de sintomas, a diminuição da mortalidade ou o aumento da expectativa de vida (THE WHOQOL GROUP, 1998).

No conceito de QV estabelecido pela OMS, destaca-se o modelo teórico de QV da satisfação, proposto por Fleck (2008). Este modelo teórico está relacionado à satisfação com os vários domínios da vida, definidos como importantes pelo próprio indivíduo, tendo em vista que a condição de satisfação é uma experiência subjetiva e está associada ao nível de expectativa de cada indivíduo. Desse modo, uma pessoa pode estar satisfeita com a sua QV tendo níveis diferentes de aquisiçōes, dependendo de suas expectativas (FLECK, 2008). 
Uma contribuição relevante para o modelo teórico de satisfação está relacionada às condiçóes com as quais o indivíduo deveria estar satisfeito para ter uma boa QV (FLECK, 2008). Nessa lógica, More (1994) e Maslow (1954) consideraram que as necessidades básicas do ser humano precisam ser contempladas para que ele possa se sentir bem. Essas precisóes compreenderam, por exemplo, saúde, mobilidade, nutrição e moradia. Portanto, ao considerar que esse modelo teórico leva em conta a existência de necessidades básicas universais, respalda-se a ideia de que é possível desenvolver um instrumento de QV a partir de uma perspectiva transcultural (FLECK, 2008).

Sustentada em uma perspectiva transcultural, a OMS construiu um instrumento de avaliação de QV denominado World Health Organization Quality of Life (WHOQOL). Esse instrumento contempla a subjetividade da avaliação, a qual está relacionada ao contexto cultural, social e ambiental. Avalia-se a percepção do respondente/pessoa e não a natureza objetiva do meio ambiente, do estado funcional ou do estado psicológico, ou mesmo, como o profissional de saúde ou um familiar avalia esses aspectos (FLECK, 2000).

A construção do instrumento WHOQOL foi resultado de uma busca pela definição do conceito de qualidade de vida. Para isso, a OMS, por meio do Grupo WHOQOL, promoveu encontros com especialistas de diversos lugares do mundo, que definiram QV como sendo a percepção que a pessoa possui acerca de sua posição na vida, no contexto de sua cultura e no sistema de valores em que vive e a respeito de suas expectativas, padróes e preocupaçóes (THE WHOQOL GROUP, 1995).

Neste sentido, os estudos acerca dos trabalhadores atuantes em regióes rurais são determinantes a fim de comprovar tais transformaçóes tecnológicas e organizacionais neste setor, que foram sucedidos por políticas desenvolvimentistas da agricultura do Brasil. De modo que passou ainda a expor os trabalhadores a situaçóes de risco novas, bem como condiçốes de trabalho e relações profissionais. Isto porque os trabalhadores agrícolas e pecuários encontram em constante exposição a diversos agentes físicos, químicos e biológicos que possuem alta potencialidade de causar acidentes (SENA; DOURADO; LIMA; ANTONIOLLI, 2018; WAHLBRINCK; BICA; REMPEL, 2017; MOURA; REMPEL; KOETZ, 2019).

O município de Imigrante possui sua economia baseada na agropecuária, indústrias e comércio, tendo destaque para a metalurgia, onde destaca-se a Metalúrgica Hassmann, e também laticínios, confecçôes, saboaria, móveis, calçados e agroindústrias. Na agricultura destaque para as culturas de milho, cana-de-açúcar, aveia, uva, tomate, soja, feijāo, batatadoce e hortaliças. Na silvicultura planta-se principalmente eucalipto, acácia e Pinus elliottii. Possui a maior estufa de cactus do sul do país, os Cactus Horst. Na pecuária destaca-se o setor de aves, suínos e gado leiteiro. Os Rebanhos em 2003 possuíam 3.920 bovinos, 25.700 suínos e 1.297.700 galináceos (IBGE, 2017).

O município pertence a região denominada Vale do Taquari. Nesta região, o grupo de pesquisa em "Sustentabilidade de propriedades produtoras de leite", da Universidade do Vale do Taquari, realiza atividades com 124 propriedades de toda a região. Nove destas propriedades são do município de Imigrante e constituem o público foco desta pesquisa. 
Tomando por base este cenário, este trabalho tem como objetivo avaliar a percepção de qualidade de vida dos produtores de leite de Imigrante/RS.

\section{MATERIAL E MÉTODOS}

A pesquisa é um estudo quali-quantitativo, exploratório e descritivo e foi utilizado como técnica entrevista com aplicaçâo de questionário. O recorte transversal. Para esse estudo, foram entrevistados produtores de leite da cidade de Imigrante, no Rio Grande do Sul. Quanto ao número de entrevistados, no início do Projeto de Pesquisa "Sustentabilidade de Propriedades Produtoras de Leite”, em 2013, foi realizado um cálculo estatístico pelo percentual de produtores de leite por município para saber quantos produtores participariam do Projeto em cada município. Na cidade de Imigrante são nove produtores que atualmente estão inclusos nas análises do projeto, pode-se ressaltar que é o município com o maior número de produtores participantes da pesquisa. A coleta de dados ocorreu no mês de agosto, onde foi marcado horário com os produtores de leite em suas residências e os mesmos foram entrevistados, utilizando-se um roteiro semiestruturado e aplicado o questionário WHOQOL, respondido pelos próprios. As respostas descritivas das entrevistas foram analisadas de forma descritiva. Os dados do WHOQOL foram tabulados em planilha Excel e foi aplicado o protocolo estabelecido para o cálculo da qualidade de vida, qualificando de acordo com a proposta de Padrão (2009).

A fim de avaliar a qualidade de vida dessa amostra, foi utilizado o instrumento proposto pela Organização Mundial da Saúde (OMS) para o sujeito adulto, o Word Health Organization Quality of Life Instrument Bref (WHOQOL-bref). Esse questionário se apresenta como uma versão reduzida do Word Health Organization Quality of Life Instrument 100 (WHOQOL-100) (SALES; FERREIRA, 2011).

A versão WHOQOL-bref adotada para esse estudo, conta com 26 questóes, 2 delas gerais sobre a qualidade de vida, e outras 24 relacionadas às facetas que formam o instrumento original (WHOQOL-100). Os dados que deram origem à versão sintetizada do estudo (WHOQOL-breff), originam de testes de campo empreendidos em 18 países do mundo. A versão brasileira do teste é traduzida e validada por parte do grupo de estudos de qualidade de vida da OMS no Brasil. Para comparação das diferenças de qualidade de vida nos escores físicos, ambiental, social e psicológico foi feita a análise de variância (ANOVA), com confirmação do Teste de Tukey, utilizando-se $\mathrm{a}=0,05$.

\section{RESULTADOS}

Compuseram a amostra sete homens $(78 \%)$ e duas mulheres (22\%). O produtor mais novo entrevistado está com 34 anos, o mais idoso com 73 anos. A idade média dos participantes é de 56 anos. Todos os entrevistados (100\%) se auto classificaram como de etnia caucasiana (branca), sendo que sete marcaram a opção "casado" e dois, a opção "solteiro" em relação ao estado civil.

Sobre o nível de escolaridade, cinco produtores marcaram que possuem ensino fundamental incompleto (67\%); dois possuem ensino fundamental completo (11\%); um possui ensino médio incompleto (11\%); e um possui ensino superior incompleto (11\%) - 
no curso de pedagogia. Perguntou-se então se praticam alguma religião e qual seria, caso a resposta fosse sim: todos responderam que praticam religióes, sete deles são evangélicos $(78 \%)$ - dois da igreja evangélica da linha luterana; e dois são da igreja católica (22\%).

Em seguida, perguntou-se há quanto tempo esses trabalhadores atuam na agricultura e se tiveram algum trabalho anterior a esse: todos os entrevistados responderam que atuam na agricultura desde sempre ou, pelo menos, há 30 anos; cinco deles (56\%) informaram que não possuem nenhum trabalho antes da agricultura; os demais (44\%) relataram trabalhos anteriores em: metalurgia, abate de frango, fábrica de calçados, doméstica e secretaria de agricultura.

Perguntou-se quantas pessoas vivem na propriedade em que se produz o leite, se os produtores possuem filhos e, em caso afirmativo, quantos deles residem na propriedade: quatro entrevistados informam que residem cinco pessoas em sua propriedade; três informam que residem duas pessoas na propriedade; um entrevistado relata que três pessoas vivem na propriedade; e um relata que quatro pessoas vivem na propriedade.

Três produtores afirmam não ter filhos, dos outros seis que têm filhos: três produtores possuem um filho; dois relatam ter dois filhos; e um produtor informa ter três filhos. Cinco produtores informam que os filhos residem na propriedade; dois informam que os filhos não residem na propriedade e não informam o motivo pelo qual isso acontece; e outros dois não responderam a essa questão. A maioria dos filhos não pretende continuar trabalhando nas atividades do campo.

Ao final os produtores comentaram se algum membro da família possui diagnóstico de doença crônica ou outra e, caso a resposta fosse positiva, quais doenças foram diagnosticadas: três produtores afirmaram não ter nenhum membro da família diagnosticado com nenhuma doença. Dos seis restantes, as doenças foram: quatro produtores relatam casos de hipertensão arterial sistêmica entre os membros da família; dois deles relatam casos de diagnósticos de doenças coronarianas; e, três relatam casos de dislipidemia (aumento do colesterol e triglicerídeos).

A média de qualidade de vida dos produtores é 82,2 (DP 7,1), o que pode ser classificada como boa. Contudo, analisado os escores de qualidade de vida nos diferentes domínios analisados, verificou-se que, no domínio físico, a média de QV é de 76,19 (DP 12,8). O domínio psicológico apresentou uma média de QV de 78,7 (DP 5,7). No domínio relaçóes sociais, a média de QV foi de 90,7 (DP 12,1). O domínio meio ambiente apresentou uma média de QV de 83,0 (DP 4,9). A média do domínio físico difere estatisticamente do domínio Social e o domínio Psicológico do Social pelo teste de Tukey p $<0,05$ (Gráfico 1). 
Gráfico 1 - Média e desvio padrão da qualidade de vida dos produtores rurais participantes da pesquisa nos domínios físico, psicológico, social e ambiental

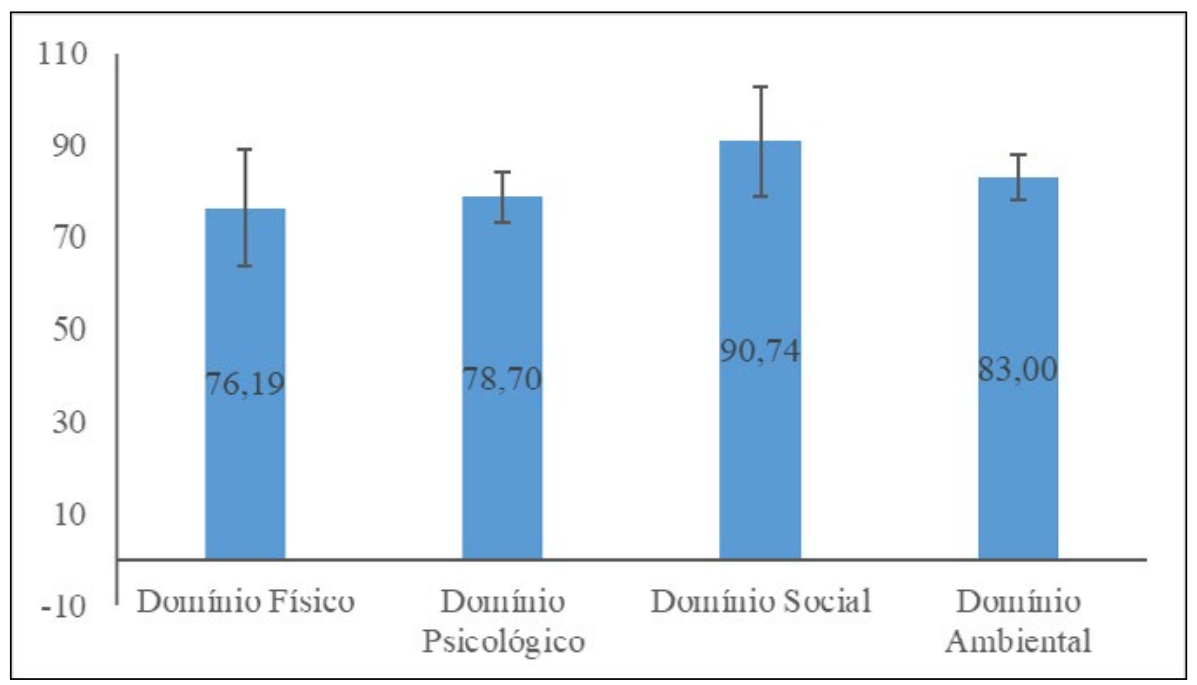

Fonte: Dados da Pesquisa (2017)

No instrumento WHOQOL-bref o domínio físico, que apresentou a menor média segundo os produtores pesquisados, é avaliado através das questóes 3, 4, 10, 15, 16, 17 e 18 que estão descritas abaixo, sendo que em cada questão é incorporada uma faceta de avaliação. Ao verificar as frequências e percentuais das facetas incorporadas no domínio físico, em relação à "dor e desconforto", verificou-se que $11 \%$ mencionaram que a dor impede bastante ou extremamente a realização de suas atividades necessárias. Quanto à "dependência de medicação ou tratamento", 22\% percebem que precisam bastante ou extremamente de algum tratamento médico para levar sua vida diária. Já para "energia e fadiga”, $11 \%$ consideraram que possuem pouca energia para seu dia a dia, e $22 \%$ possuem capacidade média de energia. Quanto à "mobilidade”, 22\% avaliaram sua capacidade de se locomover como boa. Referente à faceta "sono e repouso", 56\% estáo muito satisfeitos com seu sono. Acerca da "atividade da vida cotidiana", $45 \%$ estão nem satisfeitos nem insatisfeitos com a capacidade de desempenhar as atividades do dia-a-dia. Já sobre a "capacidade de trabalho", 33\% estão muitos satisfeitos (Tabela 1). 
Tabela 1 - Distribuição das frequências e porcentagens das questôes referentes ao domínio físico do WHOQOL-bref

\begin{tabular}{|c|c|c|c|}
\hline Questóes do Domínio Físico & Respostas & $\mathbf{N}(9)$ & $\%$ \\
\hline \multirow{5}{*}{$\begin{array}{l}\text { Q3 - Em que medida você acha } \\
\text { que sua dor (física) impede você de } \\
\text { fazer o que você precisa? }\end{array}$} & Nada & 3 & 34 \\
\hline & Muito pouco & 3 & 33 \\
\hline & Mais ou menos & 2 & 22 \\
\hline & Bastante & 1 & 11 \\
\hline & Extremamente & & ------ \\
\hline \multirow{5}{*}{$\begin{array}{l}\text { Q4 - O quanto você precisa de } \\
\text { algum tratamento médico para } \\
\text { levar sua vida diária? }\end{array}$} & Nada & & $-\cdots--$ \\
\hline & Muito pouco & 5 & 56 \\
\hline & Mais ou menos & 2 & 22 \\
\hline & Bastante & 2 & 22 \\
\hline & Extremamente & & $-\cdots--$ \\
\hline \multirow{5}{*}{$\begin{array}{l}\text { Q } \mathbf{1 0} \text { - Você tem energia suficiente } \\
\text { para seu dia a dia? }\end{array}$} & Nada & & -_---- \\
\hline & Muito pouco & 1 & 11 \\
\hline & Médio & 2 & 22 \\
\hline & Muito & 2 & 22 \\
\hline & Completamente & 4 & 45 \\
\hline \multirow{5}{*}{$\begin{array}{l}\text { Q } 15 \text { - Quão bem você é capaz de } \\
\text { se locomover? }\end{array}$} & Muito ruim & & ----- \\
\hline & Ruim & & --.--- \\
\hline & Nem ruim nem bom & 2 & 22 \\
\hline & Bom & 2 & 22 \\
\hline & Muito Bom & 5 & 56 \\
\hline \multirow{5}{*}{$\begin{array}{l}\text { Q } 16 \text { - Quão satisfeito você está } \\
\text { com seu sono? }\end{array}$} & Muito insatisfeito & & ----- \\
\hline & Insatisfeito & & --.--- \\
\hline & Nem satisfeito nem insatisfeito & 1 & 11 \\
\hline & Satisfeito & 3 & 33 \\
\hline & Muito satisfeito & 5 & 56 \\
\hline \multirow{5}{*}{$\begin{array}{l}\text { Q } 17 \text { - Quão satisfeito você } \\
\text { está com sua capacidade de } \\
\text { desempenhar as atividades do seu } \\
\text { dia a dia? }\end{array}$} & Muito insatisfeito & & ------ \\
\hline & Insatisfeito & & $-\ldots-$ \\
\hline & Nem satisfeito nem insatisfeito & 4 & 45 \\
\hline & Satisfeito & 2 & 22 \\
\hline & Muito satisfeito & 3 & 33 \\
\hline
\end{tabular}


Muito insatisfeito

Q 18 - Quão satisfeito você está com sua capacidade para o

Insatisfeito

trabalho?

Nem satisfeito nem insatisfeito

Satisfeito

4

22

Muito satisfeito

Fonte: Dados da pesquisa (2017).

O domínio das relaçóes sociais foi o melhor avaliado pelos produtores. No instrumento WHOQOL-bref, as questóes 20, 21 e 22 correspondem aos itens: relaçôes pessoais, suporte social e atividade sexual. $\mathrm{Na}$ faceta relaçóes pessoais, a maioria estava muito satisfeita (67\%) com seus amigos, parentes, conhecidos e colegas. A atividade sexual mostrou que $44 \%$ estavam satisfeitos e $56 \%$ estavam muito satisfeitos. Quanto ao suporte social, os dados revelaram que a maioria, $67 \%$, estava muito satisfeita com o apoio que recebem de seus amigos (Tabela 2).

Tabela 2 - Distribuição das frequências e porcentagens das questóes referentes ao domínio Social do WHOQOL-bref

\begin{tabular}{|c|c|c|c|}
\hline Questóes do Domínio Social & Respostas & $\mathbf{N}(9)$ & $\%$ \\
\hline \multirow{5}{*}{$\begin{array}{l}\text { Q } 20 \text { - Quão satisfeito você está } \\
\text { com suas relaçóes pessoais (amigos, } \\
\text { parentes, conhecidos, colegas)? }\end{array}$} & Muito insatisfeito & & ----- \\
\hline & Insatisfeito & & ------ \\
\hline & Nem satisfeito nem insatisfeito & & ----- \\
\hline & Satisfeito & 3 & 33 \\
\hline & Muito satisfeito & 6 & 67 \\
\hline \multirow{5}{*}{$\begin{array}{l}\text { Q } 21 \text { - Quão satisfeito você está } \\
\text { com sua vida sexual? }\end{array}$} & Muito insatisfeito & & ------ \\
\hline & Insatisfeito & & ------ \\
\hline & Nem satisfeito nem insatisfeito & & ----- \\
\hline & Satisfeito & 4 & 44 \\
\hline & Muito satisfeito & 5 & 56 \\
\hline \multirow{5}{*}{$\begin{array}{l}\text { Q22 - Quão satisfeito você está } \\
\text { com o apoio que você recebe de } \\
\text { seus amigos? }\end{array}$} & Muito insatisfeito & & ------ \\
\hline & Insatisfeito & & ----- \\
\hline & Nem satisfeito nem insatisfeito & & ------ \\
\hline & Satisfeito & 3 & 33 \\
\hline & Muito satisfeito & 6 & 67 \\
\hline
\end{tabular}

Fonte: Dados da pesquisa (2017).

O domínio psicológico, no instrumento WHOQOL-bref, corresponde aos itens de sentimentos positivos, pensar, aprender, memória e concentração, imagem corporal e aparência, sentimentos negativos e crenças pessoais, os quais săo avaliados através das questóes $5,6,7,11,19$ e 26 . Ao verificar as frequências e os percentuais das facetas incorporadas 
nas questóes do psicológico, evidenciou-se que, quanto aos sentimentos positivos, $45 \%$ consideraram que aproveitam bastante sua vida. A maioria, 56\%, percebe que sua vida tem sentido com bastante intensidade e $44 \%$ acreditam que a intensidade do sentido de vida é extrema. Também se visualizou que 33\% conseguem se concentrar completamente nas atividades, e que a maioria, 56\% se concentra pouco. Quanto à imagem corporal e à aparência, os dados revelaram que todos (100\%) aceitam sua aparência física. Referente à autoestima mostrou-se que $56 \%$ estão muito satisfeitos consigo mesmo. Acerca da frequência de sentimentos negativos, obteve-se que $67 \%$ apresentaram-nos algumas vezes, e que $22 \%$ apresentaram-nos frequentemente. Como exemplos de sentimentos negativos, citam-se mau humor, desespero, ansiedade, depressão (Tabela 3).

Tabela 3 - Distribuição das frequências e porcentagens das questóes referentes ao domínio Psicológico do WHOQOL-bref

\begin{tabular}{|c|c|c|c|}
\hline $\begin{array}{l}\text { Questóes do Domínio } \\
\text { Psicológico }\end{array}$ & Respostas & $\mathbf{N}(9)$ & $\%$ \\
\hline \multirow{5}{*}{$\begin{array}{l}\text { Q5 - O quanto você aproveita a } \\
\text { vida? }\end{array}$} & Nada & & $\begin{array}{c}-\cdots \\
-\ldots-\cdots\end{array}$ \\
\hline & Muito pouco & & $-\ldots--$ \\
\hline & Mais ou menos & 2 & 22 \\
\hline & Bastante & 4 & 45 \\
\hline & Extremamente & 3 & 33 \\
\hline \multirow{5}{*}{$\begin{array}{l}\text { Q6 - Em que medida você acha } \\
\text { que sua vida tem sentido? }\end{array}$} & Nada & & ---- \\
\hline & Muito pouco & & ----- \\
\hline & Mais ou menos & & $-\cdots$ \\
\hline & Bastante & 5 & 56 \\
\hline & Extremamente & 4 & 44 \\
\hline \multirow{5}{*}{$\begin{array}{l}\text { Q7 - O quanto você consegue se } \\
\text { concentrar? }\end{array}$} & Nada & & $-\cdots-$ \\
\hline & Muito pouco & & $-\cdots-$ \\
\hline & Mais ou menos & 5 & 56 \\
\hline & Bastante & 1 & 11 \\
\hline & Extremamente & 5 & 33 \\
\hline \multirow{5}{*}{$\begin{array}{l}\text { Q } 11 \text { - Você é capaz de aceitar sua } \\
\text { aparência física? }\end{array}$} & Nada & & ---- \\
\hline & Muito pouco & & $-\cdots-$ \\
\hline & Médio & & -.--- \\
\hline & Muito & 9 & 100 \\
\hline & Completamente & & \\
\hline \multirow{5}{*}{$\begin{array}{l}\text { Q } 19 \text { - Quão satisfeito você está } \\
\text { consigo mesmo? }\end{array}$} & Muito insatisfeito & & ---- \\
\hline & Insatisfeito & & $-\ldots--$ \\
\hline & Nem satisfeito nem insatisfeito & & ---- \\
\hline & Satisfeito & 4 & 44 \\
\hline & Muito satisfeito & 5 & 56 \\
\hline
\end{tabular}




\begin{tabular}{|c|c|c|c|}
\hline $\begin{array}{l}\text { Questóes do Domínio } \\
\text { Psicológico }\end{array}$ & Respostas & N (9) & $\%$ \\
\hline \multirow{5}{*}{$\begin{array}{l}\text { Q } 26 \text { - Com que frequência você } \\
\text { tem sentimentos negativos tais } \\
\text { como mau humor, desespero, } \\
\text { ansiedade, depressão? }\end{array}$} & Nunca & 1 & 11 \\
\hline & Algumas vezes & 6 & 67 \\
\hline & Frequentemente & 2 & 22 \\
\hline & Muito frequentemente & & ----- \\
\hline & Sempre & & --.--- \\
\hline
\end{tabular}

Fonte: Dados da pesquisa (2017).

O domínio relativo ao meio ambiente do questionário WHOQOL-brefé formado pelos itens: segurança física e proteção; ambiente no lar; recursos financeiros; cuidados de saúde e disponibilidades sociais e qualidade; oportunidade de conseguir novas informaçóes e habilidades, participação e oportunidade de recreação e lazer; ambiente físico (poluição, ruído, trânsito e clima); e transporte. Em relação à segurança física e proteção, a maioria, $56 \%$, sente-se bastante ou extremamente seguro em sua vida diária, e $11 \%$ sentem-se mais ou menos seguros. A maioria, $89 \%$, percebe seu ambiente físico como extremamente saudável. A faceta que avaliou o ambiente econômico apresentou $11 \%$ de pessoas que possuem muito pouco ou pouco dinheiro para satisfazer suas necessidades e $67 \%$ estão muito satisfeitas. A participação e oportunidade de atividade de recreação e lazer mostraram que 56\% praticam muito. A maioria está muito satisfeita com as condiçôes do local que mora (100\%), com acesso aos serviços de saúde (78\%), e com seu meio de transporte (22\%) (Tabela 4).

Tabela 4 - Distribuição das frequências e porcentagens das questóes referentes ao domínio Ambiental do WHOQOL-bref

\begin{tabular}{|c|c|c|c|}
\hline $\begin{array}{c}\text { Questóes do Domínio } \\
\text { Ambiental }\end{array}$ & Respostas & N (9) & $\%$ \\
\hline \multirow{5}{*}{$\begin{array}{l}\text { Q } 8 \text { - Quão seguro(a) você se sente } \\
\text { em sua vida diária? }\end{array}$} & Nada & & --.-- \\
\hline & Muito pouco & & -.--- \\
\hline & Mais ou menos & 1 & 11 \\
\hline & Bastante & 3 & 35 \\
\hline & Extremamente & 5 & 56 \\
\hline \multirow{5}{*}{$\begin{array}{l}\text { Q9 - Quão saudável é o seu } \\
\text { ambiente físico (clima, barulho, } \\
\text { poluição e atrativos)? }\end{array}$} & Nada & & ----- \\
\hline & Muito pouco & & ----- \\
\hline & Mais ou menos & 1 & 11 \\
\hline & Bastante & & --.-- \\
\hline & Extremamente & 8 & 89 \\
\hline \multirow{5}{*}{$\begin{array}{l}\text { Q } 12 \text { - Você tem dinheiro } \\
\text { suficiente para satisfazer suas } \\
\text { necessidades? }\end{array}$} & Nada & & ----- \\
\hline & Muito pouco & 1 & 11 \\
\hline & Médio & 1 & 11 \\
\hline & Muito & 6 & 67 \\
\hline & Completamente & 1 & 11 \\
\hline
\end{tabular}




\begin{tabular}{|c|c|c|c|}
\hline $\begin{array}{c}\text { Questóes do Domínio } \\
\text { Ambiental }\end{array}$ & Respostas & $\mathbf{N}(9)$ & $\%$ \\
\hline \multirow{5}{*}{$\begin{array}{l}\text { Q } 13 \text { - Quão disponível para você } \\
\text { estão as informaçóes que precisa no } \\
\text { dia a dia? }\end{array}$} & Nada & & ----- \\
\hline & Muito pouco & 1 & 11 \\
\hline & Médio & & ----- \\
\hline & Muito & 2 & 22 \\
\hline & Completamente & 6 & 67 \\
\hline \multirow{5}{*}{$\begin{array}{l}\text { Q } 14 \text { - Em que medida você tem } \\
\text { oportunidade de atividade de lazer? }\end{array}$} & Nada & & ---- \\
\hline & Muito pouco & & ------ \\
\hline & Médio & 1 & 11 \\
\hline & Muito & 5 & 56 \\
\hline & Completamente & 3 & 33 \\
\hline \multirow{5}{*}{$\begin{array}{l}\text { Q } 23 \text { - Quão satisfeito você está } \\
\text { com as condiçôes do local que você } \\
\text { mora? }\end{array}$} & Muito insatisfeito & & --.-- \\
\hline & Insatisfeito & & ---- \\
\hline & Nem satisfeito nem insatisfeito & & ----- \\
\hline & Satisfeito & & ------ \\
\hline & Muito satisfeito & 9 & 100 \\
\hline \multirow{5}{*}{$\begin{array}{l}\text { Q } 24 \text { - Quão satisfeito você está } \\
\text { com o seu acesso aos serviços de } \\
\text { saúde? }\end{array}$} & Muito insatisfeito & & ----- \\
\hline & Insatisfeito & & -.-.-- \\
\hline & Nem satisfeito nem insatisfeito & 1 & 11 \\
\hline & Satisfeito & 1 & 11 \\
\hline & Muito satisfeito & 7 & 78 \\
\hline \multirow{5}{*}{$\begin{array}{l}\text { Q } 25 \text { - Quão satisfeito você está } \\
\text { com seu meio de transporte? }\end{array}$} & Muito insatisfeito & & ----- \\
\hline & Insatisfeito & & ----- \\
\hline & Nem satisfeito nem insatisfeito & 6 & 67 \\
\hline & Satisfeito & 1 & 11 \\
\hline & Muito satisfeito & 2 & 22 \\
\hline
\end{tabular}

Fonte: Dados da pesquisa (2017).

Em vista das respostas oferecidas pelos produtores de leite entrevistados, nota-se que, embora sejam trabalhadores com faixas etárias, majoritariamente mais elevadas, possuem grande disposição para o trabalho e, de maneira geral, entendem sua própria qualidade de vida como positiva em diversos aspectos. Poucos foram os pontos avaliados como negativos e poucas também foram às reclamaçóes e queixas relacionadas à presença de doenças ou atendimento de saúde.

Desse modo, a questão que mais demonstrou respostas negativas associadas, foi sobre a frequência de sentimentos negativos, ansiedade, depressão, etc., em que a maioria dos entrevistados afirma sentir isso com alguma frequência. Porém, considerando que a percepção sobre a qualidade de vida é algo extremamente subjetivo e pessoal, nota-se que, 
de forma geral, a pequena amostra abordada nesse, encara sua qualidade de vida como positiva.

\section{DISCUSSÁO}

Nas entrevistas integraram mais homens do que mulheres, apresentando como idade média 56 anos. Esses dados são semelhantes aos resultados encontrados por Cavalheiro et al. (2014), que apresentaram 66\% dos entrevistados são do sexo masculino e tem idade média de 46 anos e a idade média das mulheres ficou em 52 anos, e no estudo de Moura, Rempel e Koetz (2019) 54,8\% dos produtores são homens, com idade média de 49 anos, sendo a idade média das mulheres também um pouco inferior (47,5 anos) demonstrando que na atividade leiteira, predominam homens com idade superior a das mulheres.

Quanto ao nível de escolaridade foram encontrados dados semelhantes aos resultados deste trabalho em um estudo realizado sobre a qualidade de vida de pessoas com Diabetes Mellitus na cidade de Lajeado - RS que constatou que 68,6\% dos entrevistados possuem o ensino fundamental incompleto (MORESCHI et al., 2018). Embora a público seja diferente, vale a comparação uma vez que o estudo de Moreschi et al. (2018), foi realizado em município próximo ao estudado nesta pesquisa e o público é semelhante.

Já, relacionado ao tempo de trabalho na agricultura e se já tiveram algum trabalho anterior, encontrou-se uma média semelhante a outro estudo realizado no mesmo município sobre os riscos da exposição a agrotóxicos onde a maioria declara que começou a trabalhar desde a infância na propriedade (WAHLBRINCK; BICA; REMPEL, 2017) e no município vizinho de Teutônia (REMPEL; HAETINGER, SEHNEM, 2013).

A maioria dos filhos não pretende continuar trabalhando nas atividades do campo, diferindo do estudo de Cavalheiro et al. (2014) no qual 50\% dos filhos trabalham na propriedade com os pais.

Com relação ao domínio físico, que apresentou a menor média segundo os produtores pesquisados, referente a faceta "dor e desconforto", obteve-se em outros estudos médias semelhantes, com resultado de 69,2 e $84 \%$ dos produtores mencionaram dores na coluna lombar (CAVALHEIRO et al., 2014). Dados semelhantes ao encontrado no estudo de Moura, Rempel e Koetz (2019) com produtores de leite de Rondônia, onde a média do escore de qualidade de vida no domínio físico foi de 54,9. No estudo de Moreschi (2016), mesmo não sendo com produtores rurais, mas de município próximo ao de estudo, verificou-se que $33,4 \%$ relataram que a dor impede bastante para a realização das atividades. Outros dados foram encontrados em um estudo realizado sobre a produção da cana-de-açúcar no Brasil e a saúde do trabalhador rural onde os movimentos repetitivos realizados pelos produtores causam dores no corpo e na coluna lombar, sendo presentes esses sintomas em $87,88 \%$ dos entrevistados da pesquisa (VERÇOSA; SILVA, 2017). Já no estudo sobre reflexóes de idosos sobre as relaçóes entre o trabalho rural, problemas de coluna e postura corporal na cidade de Teutônia (município vizinho ao aqui estudado), a maioria dos entrevistados (91,3\%) relatou sentir dores na coluna durante as atividades realizadas (REMPEL; HAETINGER; SEHNEM, 2013). 
Já domínio das relaçôes sociais foi o melhor avaliado pelos produtores, essa evidência está relacionada a outro estudo que também teve o melhor resultado no domínio social atingindo $80 \mathrm{em}$ uma escala até 100 (CAVALHEIRO et al., 2014). Já no estudo de Moura, Rempel e Koetz (2019) o domínio psicológico foi o que apresentou o melhor escore $(62,5)$.

O domínio psicológico, o qual a maioria percebe que sua vida tem sentido com bastante intensidade e $44 \%$ acreditam que a intensidade do sentido de vida é extrema. Resultado semelhante em um estudo onde $77,2 \%$, percebem que sua vida tem sentido com intensidade de bastante ou extremamente, e 7,4\% acreditam que a intensidade de sentido de sua vida é nada ou muito pouca (MORESCHI, 2016).

Quanto ao domínio relativo ao meio ambiente do questionário WHOQOL-bref obteve como resultados, em relação à segurança física e proteção, a maioria sente-se bastante ou extremamente seguro em sua vida diária. Todos estão muito satisfeitos com as condiçóes do local que mora. Estes dados têm uma situaçáo semelhante que foi encontrada no estudo de Moreschi (2016), onde a maioria, 70,8\%, sente-se bastante ou extremamente seguro em sua vida diária e $88 \%$ estão satisfeitos ou muito satisfeitos com as condiçóes do local que moram.

\section{CONCLUSÃO}

A percepção da qualidade de vida dos produtores rurais de propriedades leiteiras de Imigrante/RS é boa, mesmo que apresentem alguns aspectos negativos. Para os produtores entrevistados, a qualidade de vida no domínio físico é a que apresentou menores escores e o domínio social o que apresentou os maiores escores. A pesquisa aponta que mesmo sendo a qualidade de vida boa, há vários aspectos que necessitam atenção e que podem ser melhorados em especial às questóes físicas, muito vinculadas à rotina de trabalho diária que esta atividade exige.

\section{REFERÊNCIAS}

CAVALHEIRO, C.N.; REMPEL, C.; LAROQUE, L.F.S.; MACHADO, B.N.B. Perfil socioeconômico e análise da qualidade de vida dos produtores de leite da comunidade São Justino, em Juína/MT. Revista Destaques Acadêmicos - CCBS/Univates, v. 6, n. 3, p. 148-156, 2014. Disponível em: <http://www.univates.br/revistas/index.php/destaques/ article/view/425>. Acesso em: 03 fev. 2019.

FARIÑA, L. O.; BERTOLINI, G. R. F; MENEGHATTI, M. R. Relação entre a cooperativa e cooperado na agricultura familiar: a busca pela sustentabilidade econômica dos produtores de leite. Revista Metropolitana de Sustentabilidade, v. 7, n. 1, p. 108126, 2017. Disponível em: < http://www.revistaseletronicas.fmu.br/index.php/rms/ article/view/1176>. Acesso em: 09 abr. 2019.

FLECK, M. P. de A. O instrumento de avaliação de qualidade de vida da Organização Mundial da Saúde (WHOQOL-100): características e perspectivas. Ciênc. saúde coletiva, Rio de Janeiro, v. 5, n. 1, p. 33-38, 2000. 
FLECK, M. P. de A. (org.) A avaliaçáo de qualidade de vida: guia para profissionais da saúde. Porto Alegre, Artmed, 2008

IBGE - Instituto Brasileiro de Geografia e Estatística. Produçáo da Pecuária Municipal 2006. Disponível em: <http://www.ibge.gov.br>. Acesso em: 21 out. 2018.

IBGE Efetivo dos rebanhos, por tipo de rebanho, segundo a Unidade da Federação, suas Mesorregióes, Microrregióes e Municípios. 2017. Disponível em: https://www.ibge.gov. br/estatisticas/economicas/agricultura-e-pecuaria/9107-producao-da-pecuaria-municipal. html?=\&t=resultados, acesso em 12/09/2019

\section{MORESCHI, C. Qualidade de vida de pessoas com diabetes mellitus: açóes} desenvolvidas pelas estratégias saúde da família. 2016. Tese (Doutorado em Ambiente e Desenvolvimento) - Programa de Pós-Graduação em Ambiente e Desenvolvimento, Universidade do Vale do Taquari - Univates, Lajeado, 2016. Disponível em: <https:// www.univates.br/bdu/handle/10737/1136>. Acesso em: 03 fev. 2019.

MORESCHI, C.; REMPEL, C.; SIQUEIRA, D. F.; BACKES, D. S.; PISSAIA, L. F.; GRAVE, M. T. Q. Estratégias Saúde da Família: perfil/qualidade de vida de pessoas com diabetes. Revista Brasileira de Enfermagem, v. 71, n. 6, p. 3073-3080, 2018. Disponível em: <http://www.scielo.br/pdf/reben/v71n6/pt_0034-7167-reben-71-06-2899.pdf>. Acesso em: 08 abr. 2019.

MOURA, W. N.; REMPEL, C.; KOETZ, L. C. E. Qualidade e estilo de vida de produtores de leite em propriedades rurais de um município do Cone Sul de Rondônia. Cadernos Unifoa, Volta Redonda, n. 40, p. 127-137, agosto 2019.

PADRÃO, M. B.; SENS, Y. A. S. Quality of life of living kidney donors in Brazil: an evaluation by the short form-36 and the WHOQOL-bref questionnaires. Clinical Transplantation, v. 23, n. 5, p. 621-627, 2009. Disponível em: <https://onlinelibrary. wiley.com/doi/full/10.1111/j.1399-0012.2009.01048.x>. Acesso em: 08 abr. 2019.

REMPEL, C.; HAETINGER, C.; SEHNEM, E. Reflexões de idosos sobre as relações entre o trabalho rural, problemas de coluna e postura corporal. Estudos, Sociedade e Agricultura, v. 21, n. 2, p. 289-307, 2013. Disponível em: <https://www.researchgate. net/publication/261402621_Reflexoes_de_idosos_sobre_as_relacoes_entre_o_trabalho_ rural_problemas_de_coluna_e_postura_corporal >. Acesso em: 03 fev. 2018.

SALES, G.P.; FERREIRA, T.F. Aplicação do questionário "WHOQOL-bref” para avaliação da qualidade de vida nos participantes do projeto de promoção em saúde corra pela vida de São Roque do Canaã/ES. Revista Brasileira de Prescriçáo e Fisiologia do Exercício, v. 5, n. 28, p. 366-374, 2011. Disponível em: <http://www.rbpfex.com.br/ index.php/rbpfex/article/view/353 >. Acesso em: 03 fev. 2019. 
SENA, T. R. R.; DOURADO, S. S. F.; LIMA, L. V.; ANTONIOLLI, A. R. The Hearing of Rural Workers Exposed to Noise and Pesticides. Noise \& Health, v. 20, n. 92, p. 2326, 2018. Disponível em: <https://www.ncbi.nlm.nih.gov/pmc/articles/PMC5843986/>. Acesso em: 08 abr. 2019.

THE WHOQOL GROUP. Development of the World Health Organization WHOQOL-BREF Quality of Life Assessment. Psychological Medicine, v. 28, n. 3, p. 551-558, 1998. Disponível em: <https://pdfs.semanticscholar.org/e8ff/ ae53509590129240f132b354ad36e649d6bd.pdf>. Acesso em: 08 abr. 2019.

THE WHOQOL GROUP. The world health organization quality of life assessment (whoqol): position paper from the world health organization. Social Science $\&$ Medicine, v. 41, n. 10, p. 1403-1409, 1995. Disponível em: <https://www.sciencedirect. com/science/article/pii/027795369500112K>. Acesso em: 03 fev. 2019.

VERÇOSA, L. V.; SILVA, M. A. M. Cana, labor e adoecimento: a afirmação do nexo causal como uma forma de resistência. Século XXI, Revista de Ciências Sociais, v. 1, n. 7, p. 216-256, 2017. Disponível em: < https://www.trama.ufscar.br/wp-content/ uploads/2016/01/cana-labor-e-adoecimento-a-afirmacao-do-nexo-causal-como-umaforma-de-resistencia.pdf>. Acesso em: 09 abr. 2019.

WAHLBRINCK, M.G.; BICA, J.B.; REMPEL, C. Percepção dos agricultores do município de Imigrante (RS) sobre os riscos da exposição a agrotóxicos. Revista Brasileira de Ciências Ambientais, v. 44, n. 6, p. 72-84, 2017. Disponível em: <http://abes-dn.org. br/?page_id=1017>. Acesso em: 03 fev. 2019. 